\title{
Circulating angiogenic factors determined by electrochemiluminescence immunoassay in relation to the clinical features and laboratory parameters in women with pre-eclampsia
}

\author{
Attila Molvarec ${ }^{1}$, András Szarka ${ }^{1}$, Szilvia Walentin ${ }^{2}$, Endre Szűcs ${ }^{1}$, Bálint $\mathrm{Nagy}^{1}$ and János Rigó $\mathrm{Jr}^{1}$
}

The purpose of this study was to determine whether increased serum soluble fms-like tyrosine kinase-1 (sFIt-1) and decreased placental growth factor (PIGF) levels in pre-eclampsia are related to the clinical features and laboratory parameters of the patients, including markers of inflammation, endothelial activation and injury, oxidative stress and trophoblast debris. A total of 54 pre-eclamptic patients, 58 healthy pregnant and 52 healthy non-pregnant women were involved in this case-control study. Serum sFIt-1 and PIGF levels were measured by electrochemiluminescence immunoassay. Serum levels of sFIt-1 and PIGF were significantly higher in pre-eclamptic patients and healthy pregnant women than in healthy non-pregnant women. In addition, pre-eclamptic patients had significantly higher sFIt-1 levels and significantly lower PIGF concentrations compared with healthy pregnant women. According to the subgroup analyses, sFIt-1 levels were significantly higher in severely pre-eclamptic patients than in those with mild pre-eclampsia, whereas pre-eclamptic patients with fetal growth restriction or preterm onset of the disease had significantly lower PIGF concentrations compared with those without intrauterine growth restriction or with a disease onset at term. In the pre-eclamptic group, there were significant positive correlations between serum sFlt- 1 levels and systolic and diastolic blood pressure, serum levels of blood urea nitrogen and creatinine, as well as plasma levels of von Willebrand factor antigen, fibronectin and cell-free fetal DNA. Furthermore, serum PIGF concentrations of pre-eclamptic patients showed significant positive correlations with gestational age at disease onset and delivery, as well as with fetal birth weight, and significant inverse correlations with levels of blood urea nitrogen, creatinine and fibronectin. In conclusion, increased serum sFIt-1 and decreased PIGF levels are associated with blood pressure, renal and endothelial dysfunction, trophoblast deportation, as well as with a shorter duration of pregnancy, fetal growth restriction, the severity and preterm onset of the disease in pre-eclampsia. These findings indicate the central role of an angiogenic imbalance in the pathogenesis of this pregnancy-specific disorder.

Hypertension Research (2010) 33, 892-898; doi:10.1038/hr.2010.92; published online 10 June 2010

Keywords: electrochemiluminescence immunoassay; PIGF; pre-eclampsia; pregnancy; sFlt-1

\section{INTRODUCTION}

Pre-eclampsia, characterized by hypertension and proteinuria developing after midgestation in a previously normotensive woman, is a severe complication of human pregnancy with a worldwide incidence of $2-10 \% .^{1}$ It is one of the leading causes of maternal as well as perinatal morbidity and mortality, even in developed countries. Despite intensive research efforts, the etiology and pathogenesis of pre-eclampsia are not fully understood. There is an increasing body of evidence that a generalized endothelial dysfunction has a crucial role in the pathogenesis of the disease. The changes initiated by endothelial cell injury set in motion a dysfunctional cascade of coagulation, vasoconstriction and intravascular fluid redistribution that results in the clinical syndrome of pre-eclampsia. ${ }^{2}$ The development of pre-eclampsia is influenced by both genetic and environmental risk factors, suggesting its multifactorial inheritance. ${ }^{3-12}$

Soluble fms-like tyrosine kinase-1 (sFlt-1), the naturally occurring soluble form of vascular endothelial growth factor receptor 1 (VEGFR1), is produced by alternative splicing of the Flt-1 transcript, resulting in a deletion of the intracellular and transmembrane domains of Flt-1. sFlt-1 binds VEGF and placental growth factor (PIGF) with high affinity, acting as a soluble trap of these angiogenic factors. ${ }^{13}$ Placental sFlt-1 was found to be upregulated in pre-eclampsia, leading to increased circulating levels of sFlt-1 that fell after delivery. Increased serum sFlt-1 levels in patients with pre-eclampsia

${ }^{1}$ First Department of Obstetrics and Gynecology, Semmelweis University, Budapest, Hungary and ${ }^{2}$ Central Laboratory, Kútvölgyi Clinical Center, Semmelweis University, Budapest, Hungary

Correspondence: Dr A Molvarec, First Department of Obstetrics and Gynecology, Semmelweis University, Hangya lépcső 9, Budapest H-1121, Hungary E-mail: molvarec@freemail.hu

Received 25 February 2010; revised 28 March 2010; accepted 9 April 2010; published online 10 June 2010 
were associated with decreased circulating levels of free VEGF and PlGF. Excess sFlt-1 in pre-eclamptic serum impaired angiogenesis in vitro that could be restored by exogenous VEGF and PlGF. In addition, administration of sFlt-1 to pregnant rats induced hypertension, proteinuria and glomerular endotheliosis, the hallmarks of pre-eclampsia. ${ }^{14}$ On the other hand, treatment with recombinant VEGF or PlGF alleviated these symptoms in animal models of pre-eclampsia. ${ }^{15,16}$ Experimental data indicate that placental hypoxia is responsible for increased sFlt-1 expression in pre-eclamptic placenta. ${ }^{17,18}$ Furthermore, it has been shown that increased circulating levels of sFlt-1 and reduced levels of free PlGF predict the subsequent development of pre-eclampsia. ${ }^{19}$ Circulating sFlt-1 and PlGF levels are also altered in women with gestational proteinuria, but to a lesser degree than in those with pre-eclampsia. ${ }^{20,21}$

In this study, we determined serum sFlt- 1 and PlGF levels in healthy non-pregnant and pregnant women and pre-eclamptic patients. We also measured several markers of processes involved in the pathogenesis of pre-eclampsia, and investigated whether the clinical characteristics and laboratory parameters of the study participants, including markers of inflammation (C-reactive protein (CRP)), endothelial activation (von Willebrand factor antigen (VWF:Ag)) and endothelial injury (fibronectin), oxidative stress (malondialdehyde) and trophoblast debris (cell-free fetal DNA), were related to their serum sFlt-1 and PlGF levels.

\section{METHODS}

\section{Study patients}

Our study was designed using a case-controlled approach. A total of 54 pre-eclamptic patients, 58 healthy pregnant women with uncomplicated pregnancies and 52 healthy non-pregnant women were involved in the study. The study participants were enrolled in the First Department of Obstetrics and Gynecology and in the Department of Obstetrics and Gynecology of Kútvölgyi Clinical Center, at the Semmelweis University, Budapest, Hungary. All women were Caucasian and resided in the same geographic area in Hungary. The pre-eclamptic patients and healthy pregnant women were matched on the basis of maternal age and gestational age at blood draw, and they were selected accordingly from the previously reported groups of 93 pre-eclamptic patients and 176 healthy pregnant women. ${ }^{22,23}$ Exclusion criteria were multifetal gestation, chronic hypertension, diabetes mellitus, autoimmune disease, angiopathy, renal disorder, maternal or fetal infection and fetal congenital anomaly. The healthy non-pregnant women were consecutively selected in the early follicular phase of their menstrual cycle (between cycle days 3 and 5), and none of them received hormonal contraception. The women were fasting, none of the pregnant women were in active labor, and none had rupture of membranes.

Pre-eclampsia was defined by increased blood pressure $(\geqslant 140 \mathrm{~mm} \mathrm{Hg}$ systolic or $\geqslant 90 \mathrm{~mm} \mathrm{Hg}$ diastolic on $\geqslant 2$ occasions at least $6 \mathrm{~h}$ apart) that occurred after 20 weeks of gestation in a woman with previously normal blood pressure, accompanied by proteinuria ( $\geqslant 0.3 \mathrm{~g}$ for $24 \mathrm{~h}$ or $\geqslant 1+$ on dipstick in the absence of urinary tract infection). Blood pressure returned to normal by 12 weeks postpartum in each pre-eclamptic study patient. Pre-eclampsia was regarded as severe if any of the following criteria was present: blood pressure $\geqslant 160 \mathrm{~mm} \mathrm{Hg}$ systolic or $\geqslant 110 \mathrm{~mm} \mathrm{Hg}$ diastolic, or proteinuria $\geqslant 5 \mathrm{~g}$ for $24 \mathrm{~h}$ (or $\geqslant 3+$ on dipstick). Pregnant women with eclampsia or HELLP syndrome (hemolysis, elevated liver enzymes and low platelet count) were not enrolled in this study. Fetal growth restriction was diagnosed if the fetal birth weight was below the 10th percentile for gestational age and gender, based on Hungarian birth weight percentiles. ${ }^{24}$

The study protocol was approved by the Regional and Institutional Committee of Science and Research Ethics of the Semmelweis University, and written informed consent was obtained from each patient. The study was conducted in accordance with the Declaration of Helsinki.

\section{Biological samples}

Blood samples were obtained from an antecubital vein into plain, as well as EDTA or sodium citrate anticoagulated tubes, and then centrifuged at room temperature with a relative centrifugal force of $3000 \mathrm{~g}$ for $10 \mathrm{~min}$. The aliquots of serum and plasma were stored at $-80^{\circ} \mathrm{C}$ until the analyses.

\section{Laboratory methods}

Serum total sFlt-1 and biologically active PlGF levels were measured by electrochemiluminescence immunoassay (Elecsys; Roche, Mannheim, Germany, Cat. No. 05109523 and 05144671 , respectively $)^{25,26}$ on a Cobas e 411 analyzer (Roche). Standard laboratory parameters (clinical chemistry) and CRP levels were determined by an autoanalyzer (Cobas Integra 800; Roche) using the manufacturer's kits. Plasma VWF:Ag levels were quantified by enzyme-linked immunosorbent assay (Dakopatts, Glostrup, Denmark), and plasma fibronectin concentration using nephelometry (Dade Behring, Marburg, Germany), according to the manufacturer's instructions. After extracting DNA with the silica adsorption method, the amount of cell-free fetal DNA in maternal plasma was determined in patients with male newborns by quantitative real-time PCR analysis of the SRY (sex-determining region $Y$ ) gene, as we described previously. ${ }^{27}$ Plasma malondialdehyde levels were measured by the thiobarbituric acid-based colorimetric assay. ${ }^{28}$

\section{Statistical analysis}

The normality of continuous variables was assessed using the Shapiro-Wilk $W$-test. As the continuous variables were not normally distributed, nonparametric statistical methods were used. To compare continuous variables between two groups, the Mann-Whitney $U$-test was applied, whereas to compare them among multiple groups, the Kruskal-Wallis analysis of variance by ranks test was performed. Multiple comparisons of mean ranks for all groups were carried out as post hoc tests. Fisher's exact and Pearson's $\chi^{2}$-tests were used to compare categorical variables between groups. Spearman's rank order correlation was applied to calculate correlation coefficients. The diagnostic accuracy of serum sFlt-1 and PlGF measurements in pre-eclampsia was evaluated with the receiver operating characteristic curve analysis.

Statistical analyses were performed using the following softwares: STATISTICA (version 8.0; StatSoft, Tulsa, OK, USA), Statistical Package for the Social Sciences (version 15.0 for Windows; SPSS, Chicago, IL, USA) and MedCalc for Windows (version 10.0.1.0; MedCalc Software, Mariakerke, Belgium). For all statistical analyses, $P<0.05$ was considered statistically significant.

In the article, data are reported as median (25-75 percentile) for continuous variables and as number (percentage) for categorical variables.

\section{RESULTS}

\section{Patient characteristics}

The clinical characteristics of the study participants are described in Table 1. There was no statistically significant difference in terms of age among the study groups. Furthermore, no significant differences were observed in gestational age at blood collection and the percentage of primiparas between pre-eclamptic patients and healthy pregnant women. However, as shown in Table 1, body mass index, smoking status, systolic and diastolic blood pressures differed significantly among the three study groups. The gestational age at delivery and the fetal birth weight were significantly lower in the pre-eclamptic group compared with the group of healthy pregnant women. Fetal growth restriction was absent in healthy pregnant women, whereas the frequency of this condition was $16.7 \%$ in the pre-eclamptic group. In all, 19 women had severe pre-eclampsia and 28 patients experienced preterm onset ( $<37$ weeks) of the disease.

\section{Laboratory parameters}

The laboratory parameters of the study subjects are shown in Table 2. As can be seen in the table, most of the measured laboratory parameters differed significantly among the three study groups except for serum aspartate aminotransferase activity. Serum levels of sFlt-1 
Table 1 Clinical characteristics of healthy non-pregnant and pregnant women and pre-eclamptic patients

\begin{tabular}{|c|c|c|c|}
\hline & $\begin{array}{l}\text { Healthy non-pregnant } \\
\text { women }(\mathrm{n}=52)\end{array}$ & $\begin{array}{l}\text { Healthy pregnant } \\
\text { women }(n=58)\end{array}$ & $\begin{array}{l}\text { Pre-eclamptic } \\
\text { patients }(\mathrm{n}=54)\end{array}$ \\
\hline Age (years) & $28(25-34)$ & $30(28-32)$ & $29(26-33)$ \\
\hline Smokers & $12(23.1 \%)$ & $0(0 \%)^{\mathrm{a}}$ & $3(5.6 \%)^{c}$ \\
\hline Primiparas & NA & $35(60.3 \%)$ & $33(61.1 \%)$ \\
\hline Systolic blood pressure at blood draw $(\mathrm{mm} \mathrm{Hg})$ & $110(110-120)$ & $110(105-120)$ & $160(153-180)^{a, b}$ \\
\hline Gestational age at blood draw (weeks) & NA & $36(36-37)$ & $37(36-39)$ \\
\hline Gestational age at delivery (weeks) & NA & $39(38-40)$ & $38(37-39)^{b}$ \\
\hline Fetal birth weight $(\mathrm{g})$ & NA & $3450(3150-3700)$ & $3075(2450-3450)^{\mathrm{b}}$ \\
\hline Fetal growth restriction & NA & $0(0 \%)$ & $9(16.7 \%)^{d}$ \\
\hline
\end{tabular}

Abbreviations: BMI, body mass index; NA, not applicable.

Data are presented as median (25-75 percentile) for continuous variables and as number (percentage) for categorical variables.

a $P<0.001$ vs. healthy non-pregnant women.

${ }^{b} P<0.001$ pre-eclamptic patients vs. healthy pregnant women.

${ }^{c} P<0.05$ vs. healthy non-pregnant women.

${ }^{d} P<0.05$ pre-eclamptic patients $v s$. healthy pregnant women.

Table 2 Laboratory parameters of healthy non-pregnant and pregnant women and pre-eclamptic patients

\begin{tabular}{|c|c|c|c|}
\hline & $\begin{array}{c}\text { Healthy non-pregnant } \\
\text { women }(\mathrm{n}=52)\end{array}$ & $\begin{array}{l}\text { Healthy pregnant } \\
\text { women }(\mathrm{n}=58)\end{array}$ & $\begin{array}{c}\text { Pre-eclamptic } \\
\text { patients }(\mathrm{n}=54)\end{array}$ \\
\hline Serum BUN level $\left(\mathrm{mmol}^{-1}\right)$ & $4.3(3.6-4.8)$ & $2.8(2.0-3.3)^{a}$ & $3.5(2.7-4.2)^{b, c}$ \\
\hline Serum bilirubin level $\left(\mu \mathrm{mol} \mathrm{I}^{-1}\right)$ & $8.7(6.6-12.4)$ & $5.4(4.0-6.8)^{\mathrm{a}}$ & $7.4(5.8-9.4)^{b, c}$ \\
\hline Serum AST activity $\left(\mathrm{UI}^{-1}\right)$ & $17(15-20)$ & $19(17-21)$ & $19(15-24)$ \\
\hline Serum ALT activity $\left(\mathrm{U} \mathrm{I}^{-1}\right)$ & $15(12-17)$ & $12(10-15)^{b}$ & $15(11-19)^{c}$ \\
\hline Plasma fibronectin level $\left(\mathrm{gl}^{-1}\right)$ & NM & $0.37(0.31-0.47)$ & $0.56(0.40-0.82)^{d}$ \\
\hline Plasma malondialdehyde level $\left(\mathrm{nmol} \mathrm{ml^{-1 } )}\right.$ & NM & $15.36(8.84-18.61)$ & $18.58(15.84-20.58)^{c}$ \\
\hline Plasma cell-free fetal DNA level $\left(p g \mu^{-1}\right)$ & NM & $0.002(0.0-0.172)^{\mathrm{e}}$ & $0.076(0.033-0.408)^{f, c}$ \\
\hline Serum sFlt-1 level (pg ml-1) & $76.3(67.1-83.6)$ & $3252(2509-4751)^{a}$ & $6814(3736-12720)^{\mathrm{a}, \mathrm{d}}$ \\
\hline Serum PIGF level $\left(\mathrm{pg} \mathrm{ml}^{-1}\right)$ & $16.2(14.0-18.0)$ & $183(126-307)^{\mathrm{a}}$ & $98.0(63.7-146)^{\mathrm{a}, \mathrm{d}}$ \\
\hline Serum sFIt-1/PIGF ratio & $4.79(3.82-5.52)$ & $15.6(8.52-36.6)^{\mathrm{a}}$ & $70.5(31.8-144)^{a, d}$ \\
\hline
\end{tabular}

Abbreviations: ALT, alanine aminotransferase; AST, aspartate aminotransferase; BUN, blood urea nitrogen; CRP, C-reactive protein; DNA, deoxyribonucleic acid; NM, not measured; PIGF, placental growth factor; sFlt-1, soluble fms-like tyrosine kinase-1; VWF:Ag, von Willebrand factor antigen. Data are presented as median (25-75 percentile).

${ }^{a} P<0.001$ vs. healthy non-pregnant women.

b $P<0.05$ vs. healthy non-pregnant women.

c $P<0.05$ pre-eclamptic patients vs. healthy pregnant women.

d $P<0.001$ pre-eclamptic patients vs. healthy pregnant women.

$\mathrm{e}_{n=19}$.

${ }^{\mathrm{f}} n=30$.

and PlGF, as well as sFlt-1/PlGF ratio, were significantly higher in healthy pregnant than in non-pregnant women. Pre-eclamptic patients had significantly higher sFlt-1 levels and sFlt-1/PlGF ratio and significantly lower PlGF concentrations when compared with healthy pregnant women. Moreover, their sFlt-1 and PlGF levels and sFlt-1/ PlGF ratio were significantly higher than those of healthy nonpregnant women.

According to the subgroup analyses (Table 3), severely pre-eclamptic patients had significantly higher sFlt-1 levels when compared to those with mild pre-eclampsia $(P<0.05)$. In addition, pre-eclamptic patients with fetal growth restriction or onset of the disease before term ( $<37$ weeks of gestation) had significantly lower PlGF concentrations than those without intrauterine growth restriction or with a disease onset at term ( $\geqslant 37$ weeks; $P<0.05$ for both).
Relationship of clinical characteristics and laboratory parameters of the study subjects with their serum sFlt-1 and PIGF levels

We also investigated whether the clinical characteristics and laboratory parameters of the study participants were related to their serum sFlt-1 and PlGF levels by calculating Spearman's rank order correlation coefficients (continuous variables) or by Mann-Whitney $U$-test (categorical variables). In healthy non-pregnant women, we found a statistically significant negative correlation between serum PlGF concentrations and systolic blood pressure (Spearman's $R=-0.38$, $P<0.05)$. In the group of healthy pregnant women, primiparas had significantly higher serum sFlt-1/PlGF ratio than multiparas (median (25-75 percentile), 18.5 (10.5-43.2) vs. 13.2 (5.08-24.7), $P<0.05)$. Serum sFlt-1 levels of healthy pregnant women showed significant positive correlations with serum creatinine levels $(R=0.48, P<0.05)$, 
Table 3 Serum levels of sFIt-1 and PIGF and sFIt-1/PIGF ratio in the subgroups of pre-eclamptic patients

\begin{tabular}{|c|c|c|c|}
\hline & $\begin{array}{l}\text { Serum sFlt-1 } \\
\text { level }\left(\mathrm{pg} \mathrm{m}^{-1}\right)\end{array}$ & $\begin{array}{l}\text { Serum PIGF } \\
\text { level }\left(\mathrm{pg} \mathrm{m}^{-1}\right)\end{array}$ & $\begin{array}{c}\text { Serum } \\
\text { sFIt-1/PIGF ratio }\end{array}$ \\
\hline Mild pre-eclampsia $(n=35)$ & $6113(3697-8481)$ & $98.6(59.3-146)$ & $58.8(25.6-134)$ \\
\hline Pre-eclampsia without IUGR ( $n=45$ ) & $6689(3736-12611)$ & $98.9(68.0-146)$ & $68.6(31.8-128)$ \\
\hline Pre-eclampsia with IUGR $(n=9)$ & 8903 (4857-15847) & $70.1(37.6-104)$ & $144(54.5-422)$ \\
\hline Pre-eclampsia with an onset $\geqslant 37$ weeks $(n=26)$ & $7044(4498-12720)$ & $116(91.8-176)$ & 70.5 (32.9-109) \\
\hline
\end{tabular}

Abbreviations: IUGR, intrauterine growth restriction; PIGF, placental growth factor; sFIt-1, soluble fms-like tyrosine kinase-1.

Data are presented as median (25-75 percentile).

Significant differences are shown in bold.

Table 4 Correlation coefficients between clinical characteristics and laboratory parameters of pre-eclamptic patients and their serum sFIt-1, PIGF levels and sFIt-1/PIGF ratio

\begin{tabular}{|c|c|c|c|}
\hline & $\begin{array}{c}\text { Serum sFlt-1 } \\
\text { level }\end{array}$ & $\begin{array}{c}\text { Serum PIGF } \\
\text { level }\end{array}$ & $\begin{array}{c}\text { Serum sFlt-1/ } \\
\text { PIGF ratio }\end{array}$ \\
\hline Age & -0.01 & -0.08 & 0.02 \\
\hline BMI at blood draw & -0.22 & 0.28 & -0.29 \\
\hline Systolic blood pressure & 0.31 & -0.23 & 0.35 \\
\hline Diastolic blood pressure & 0.35 & -0.07 & 0.30 \\
\hline Gestational age at disease onset & -0.07 & 0.30 & -0.21 \\
\hline Gestational age at blood draw & -0.07 & 0.28 & -0.18 \\
\hline Gestational age at delivery & -0.25 & 0.40 & -0.36 \\
\hline Fetal birth weight & -0.16 & 0.41 & -0.30 \\
\hline Serum BUN level & 0.52 & -0.48 & 0.58 \\
\hline Serum creatinine level & 0.57 & -0.30 & 0.55 \\
\hline Serum bilirubin level & -0.11 & 0.22 & -0.20 \\
\hline Serum AST activity & 0.27 & -0.05 & 0.21 \\
\hline Serum ALT activity & 0.24 & -0.01 & 0.19 \\
\hline Serum CRP level & -0.25 & 0.09 & -0.22 \\
\hline Plasma VWF:Ag level & 0.46 & -0.10 & 0.35 \\
\hline Plasma fibronectin level & 0.61 & -0.30 & 0.55 \\
\hline Plasma malondialdehyde level & 0.02 & -0.09 & 0.01 \\
\hline Plasma cell-free fetal DNA level & 0.47 & -0.29 & 0.45 \\
\hline
\end{tabular}

Abbreviations: ALT, alanine aminotransferase; AST, aspartate aminotransferase; BMI, body mass index; BUN, blood urea nitrogen; CRP, C-reactive protein; DNA, deoxyribonucleic acid; PIGF, placental growth factor; sFlt-1, soluble fms-like tyrosine kinase-1; VWF:Ag, von Willebrand factor antigen.

Significant correlations are shown in bold.

as well as with plasma levels of VWF:Ag $(R=0.42, P<0.05)$ and fibronectin $(R=0.50, P<0.001)$. A significant positive correlation was observed between PlGF levels of healthy pregnant women and fetal birth weight $(R=0.30, P<0.05)$, whereas their PlGF and CRP concentrations correlated inversely with each other $(R=-0.32, P<0.05)$. As shown in Table 4 , in the pre-eclamptic group, there were significant positive correlations between serum sFlt-1 levels and systolic and diastolic blood pressure, serum levels of blood urea nitrogen and creatinine, as well as plasma levels of VWF:Ag, fibronectin and cell-free fetal DNA. Furthermore, serum PlGF concentrations of pre-eclamptic patients showed significant positive correlations with gestational age at disease onset and delivery, as well as with fetal birth weight, and significant inverse correlations with serum levels of blood urea nitrogen, creatinine and plasma levels of fibronectin. There was no other relationship between clinical features and measured laboratory parameters of the study subjects and their serum sFlt-1 and PlGF levels in either study group.

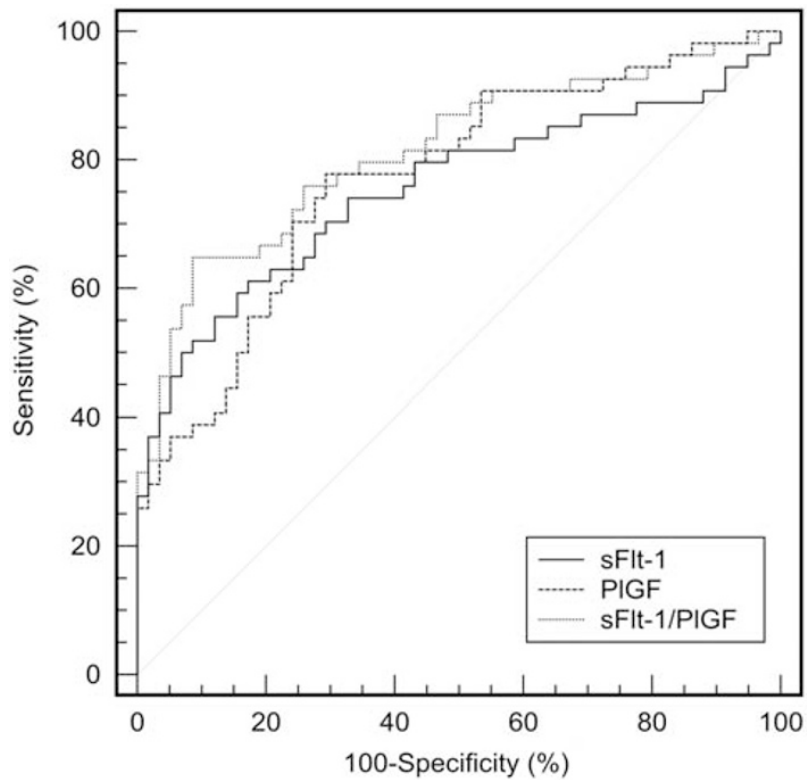

Figure 1 Receiver operating characteristic (ROC) curves of serum soluble fms-like tyrosine kinase-1 (sFlt-1, continuous line), placental growth factor (PIGF, dashed line) levels and their ratio (sFIt-1/PIGF ratio, dotted line) to discriminate between pre-eclamptic patients and healthy pregnant women.

\section{Diagnostic accuracy of serum sFlt-1 and PIGF measurements in pre-eclampsia}

Using the receiver operating characteristic curve analysis, we determined cutoff values for sFlt- 1 and PlGF concentrations and their ratio to discriminate pre-eclamptic patients from healthy pregnant women. The sensitivities and specificities of these cutoff points were as follows: for high sFlt-1 level $\left(>4165 \mathrm{pg} \mathrm{ml}^{-1}\right.$ ) 74.1 and 67.2\%; for low PlGF level $\left(<146 \mathrm{pg} \mathrm{ml}^{-1}\right) 77.8$ and $70.7 \%$; and for high sFlt-1/PlGF ratio (>31.2) 75.9 and $74.1 \%$, respectively.

We also compared the diagnostic performance of serum sFlt-1 and PlGF concentrations and their ratio in pre-eclampsia. As shown in Figure 1, the area under the receiver operating characteristic curve (AUC) of sFlt-1/PlGF ratio was significantly higher than that of sFlt-1 and PlGF levels (area under the curve with 95\% confidence interval for sFlt-1/PlGF ratio, sFlt-1 and PlGF levels were $0.81(0.73-0.88) v s$. $0.75(0.66-0.83)$ and $0.77(0.68-0.85)$, respectively; $P<0.05$ for both).

\section{DISCUSSION}

In this study, elevated serum sFlt-1 and decreased serum PlGF concentrations determined by electrochemiluminescence immunoassay were found to be associated with systolic and diastolic blood 
pressure, renal and endothelial dysfunction, trophoblast deportation process, as well as with a shorter duration of pregnancy, fetal growth restriction, the severity and preterm onset of the disease in pre-eclampsia. However, maternal age, body mass index, smoking status, parity, gestational age at blood collection, liver function parameters, as well as markers of inflammation and oxidative stress were not related to circulating levels of angiogenic factors in our pre-eclamptic patients.

VEGF and PlGF are potent angiogenic proteins involved both in angiogenesis (the growth of new blood vessels) and in the maintenance of endothelial cell health in the basal state. ${ }^{13}$ As the maternal syndrome of pre-eclampsia is characterized by a generalized endothelial dysfunction, we examined whether serum levels of the anti-angiogenic sFlt-1 or the angiogenic PlGF are related to the markers of endothelial activation (VWF:Ag) and injury (fibronectin) in pre-eclampsia. ${ }^{29,30}$ In this study, significant correlations were found between levels of these angiogenic/anti-angiogenic factors and endothelial markers in both normal pregnancy and pre-eclampsia. In addition, blood pressure values and the severity of pre-eclampsia were also related to serum sFlt-1 levels. These findings denote that VEGF and PlGF are essential for endothelial integrity in normal pregnancy, and that an imbalance between angiogenic and anti-angiogenic proteins has a central role in the pathogenesis of pre-eclampsia.

VEGF seems to be particularly important in maintaining the health of fenestrated endothelium, which is found in organs disproportionally affected in pre-eclampsia: the kidney (glomeruli), liver (sinusoids) and brain. ${ }^{13}$ Administration of anti-VEGF neutralizing antibodies or sFlt-1 to experimental animals induced endothelial damage in the glomerulus. ${ }^{31,32}$ Indeed, sFlt-1 levels correlated strongly with renal function parameters in both our healthy pregnant women and pre-eclamptic patients. Furthermore, decreased serum PlGF levels were associated with renal dysfunction in pre-eclampsia, which suggests that PlGF might also have a renal protective effect. Although no significant relationship was observed between the measured angiogenic factors and liver function parameters in our study groups, patients with HELLP syndrome were not enrolled in this study.

The placenta appears to be the major source of sFlt- 1 in normal pregnancy, ${ }^{33}$ which might explain the considerably higher sFlt-1 levels in the peripheral circulation of pregnant when compared with nonpregnant women. In pre-eclampsia, circulating sFlt-1 levels further increase because of the release of this anti-angiogenic protein from the hypoxic placenta. ${ }^{17}$ Interestingly, in the third trimester of normal pregnancy, syncytiotrophoblast sheds placental debris into the maternal circulation with elevated amounts, ${ }^{34}$ which coincides with an increase in serum sFlt-1 levels. ${ }^{19,35}$ The mass of this trophoblast debris can be assessed by the measurement of copies of cell-free fetal DNA in the maternal plasma. A significant elevation was shown in pre-eclampsia compared with normal pregnancy before and after the onset of the clinical symptoms as well. ${ }^{36-38}$ The significant correlation between circulating levels of sFlt-1 and cell-free fetal DNA observed in our pre-eclamptic group implies that trophoblast deportation process is responsible-at least partly-for increased sFlt-1 levels in this pregnancy-specific disorder. Nevertheless, peripheral blood mononuclear cells obtained from women with pre-eclampsia produced significantly higher amounts of sFlt-1 than those from normal pregnant women, suggesting that these cells might serve as an extra-placental source of sFlt-1 in pre-eclampsia. ${ }^{39}$

Another intriguing finding of our study is that pre-eclamptic patients with fetal growth restriction had significantly lower PlGF concentrations than those without. Pre-eclamptic cases with intrauterine growth restriction are characterized by profound reductions in placental perfusion. ${ }^{40}$ As cultured trophoblast cells expressed and secreted less PlGF under hypoxic conditions, ${ }^{41,42}$ diminished serum PlGF concentrations might reflect extensive placental ischemia in intrauterine growth restriction-complicated pre-eclampsia. On the other hand, decreased placental PlGF levels could also have a role in placental dysfunction, contributing to the development of fetal growth restriction..$^{43}$ Placental factors are particularly important in the pathogenesis of preterm pre-eclampsia, which was also associated with a significantly lower PlGF concentration in our study. The importance of PIGF in normal placental function is further supported by the significant positive correlation between PlGF levels and fetal birth weight observed in healthy pregnant women. It is noteworthy that PlGF concentrations of pre-eclamptic patients rose with increasing duration of pregnancy as expressed by the gestational age at the time of delivery, indicating a prognostic value of PlGF measurement in overt pre-eclampsia.

The significantly higher sFlt-1/PlGF ratio found in healthy primiparas is consistent with previous observations, and might account-at least in part-for the increased risk of primiparas for developing pre-eclampsia. ${ }^{44}$ Serum sFlt- 1 and PlGF levels are known to rise and decrease during the third trimester of pregnancy, respectively. ${ }^{19,35}$ Cigarette smoking was previously shown to be associated with lower maternal sFlt-1 concentrations in uncomplicated pregnancy and pre-eclampsia. ${ }^{45}$ In addition, overweight women with pre-eclampsia were demonstrated to have lower levels of sFlt-1 and higher levels of PlGF than pre-eclamptic women of normal weight. ${ }^{46}$ Nevertheless, the narrow range of gestational age at blood collection, as well as the low number of smokers and pre-eclamptic patients of normal weight in this study, did not allow us to confirm these data.

It has been recently reported that inflammatory stimuli can also upregulate sFlt-1 production by the placenta. ${ }^{47,48}$ However, as serum sFlt-1 levels did not correlate with CRP concentrations in our study groups, systemic inflammation characteristic of both the third trimester of normal pregnancy and pre-eclampsia does not seem to substantially contribute to increased sFlt-1 production. We detected only a slight inverse correlation between serum PlGF and CRP levels in healthy pregnant women, the clinical significance of which remains to be determined. In this study, systemic oxidative stress was also not associated with the angiogenic imbalance in pre-eclampsia, as indicated by the lack of correlations between circulating levels of malondialdehyde and angiogenic proteins. Nevertheless, the relationship of circulating sFlt-1 and PlGF with other markers of inflammation and oxidative stress should also be investigated in future studies to justify these negative findings.

In accordance with previous reports, ${ }^{25}$ in our study, the sFlt-1/PlGF ratio had better diagnostic accuracy in pre-eclampsia than measuring sFlt-1 or PlGF levels alone. As shown by the sensitivity and specificity values, pre-eclampsia does not develop in all women with high sFlt-1 or low PlGF levels, and it also occurs in some women with low sFlt-1 and high PlGF levels. Several genetic, behavioral and environmental factors need to interact to produce the clinical picture of this multifactorial disorder. Other angiogenic factors, such as transforming growth factor- $\beta 1$ and angiopoietins 1 and 2 , as well as their soluble receptors (soluble endoglin and sTie-2), have also been implicated in the pathogenesis of pre-eclampsia. ${ }^{49-52}$ Interestingly, recent data suggest different profiles of circulating angiogenic factors in earlyand late-onset pre-eclampsia. ${ }^{53,54}$ The latter is characterized by lower sFlt-1/PlGF ratio, and adipocytokines, such as adiponectin, might also be involved in its pathogenesis. ${ }^{55,56}$ It is notable that the majority of our pre-eclamptic patients were overweight, had late onset 
$(\geqslant 34$ weeks) and mild form of the disease, which might also account for the observed sensitivity and specificity values.

In conclusion, increased serum sFlt-1 and decreased PlGF levels are associated with blood pressure, renal and endothelial dysfunction, trophoblast deportation, as well as with a shorter duration of pregnancy, fetal growth restriction, the severity and preterm onset of the disease in pre-eclampsia. These findings indicate the central role of an angiogenic imbalance in the pathogenesis of this pregnancyspecific disorder.

\section{ACKNOWLEDGEMENTS}

We thank Veronika Makó, László Cervenak, Krisztián Balogh and Miklós Mézes for measuring plasma von Willebrand factor antigen and malondialdehyde concentrations.

1 Duckitt K, Harrington D. Risk factors for pre-eclampsia at antenatal booking: systematic review of controlled studies. BMJ 2005; 330: 565.

2 Roberts JM, Taylor RN, Musci TJ, Rodgers GM, Hubel CA, McLaughlin MK. Preeclampsia: an endothelial cell disorder. Am J Obstet Gynecol 1989; 161: 1200-1204.

3 Ohkuchi A, Iwasaki R, Suzuki H, Hirashima C, Takahashi K, Usui R, Matsubara S, Minakami H. Suzuki M. Normal and high-normal blood pressures, but not body mass index, are risk factors for the subsequent occurrence of both preeclampsia and gestational hypertension: a retrospective cohort study. Hypertens Res 2006; 29: 161-167.

4 Molvarec A, Jermendy A, Kovacs M, Prohaszka Z, Rigo J Jr. Toll-like receptor 4 gene polymorphisms and preeclampsia: lack of association in a Caucasian population. Hypertens Res 2008; 31: 859-864.

5 Canto P, Canto-Cetina T, Juarez-Velazquez R, Rosas-Vargas H, Rangel-Villalobos $H$, Canizales-Quinteros S, Velazquez-Wong AC, Villarreal-Molina MT, Fernandez G, Coral-Vazquez R. Methylenetetrahydrofolate reductase C677T and glutathione S-transferase P1 A313G are associated with a reduced risk of preeclampsia in Maya-Mestizo women. Hypertens Res 2008; 31: 1015-1019.

6 Zafarmand MH, Franx A, Sabour S, van der Schouw YT, Grobbee DE, de Leeuw PW, Bots $M L$. The M235T variant of the angiotensinogen gene is related to development of selfreported hypertension during pregnancy: the Prospect-EPIC cohort study. Hypertens Res 2008; 31: 1299-1305.

7 Hirashima C, Ohkuchi A, Matsubara S, Suzuki H, Takahashi K, Usui R, Suzuki M. Alteration of serum soluble endoglin levels after the onset of preeclampsia is more pronounced in women with early-onset. Hypertens Res 2008; 31: 1541-1548.

8 de Lima TH, Sass N, Mattar R, Moron AF, Torloni MR, Franchim CS, Daher S. Cytokine gene polymorphisms in preeclampsia and eclampsia. Hypertens Res 2009; 32 565-569.

9 Molvarec A, Kalabay L, Derzsy Z, Szarka A, Halmos A, Stenczer B, Arnaud P, Karadi I, Prohaszka Z, Rigo J Jr. Preeclampsia is associated with decreased serum alpha(2)-HS glycoprotein (fetuin-A) concentration. Hypertens Res 2009; 32: 665-669.

10 Molvarec A, Rigo J Jr, Lazar L, Balogh K, Mako V, Cervenak L, Mezes M, Prohaszka Z. Increased serum heat-shock protein 70 levels reflect systemic inflammation, oxidative stress and hepatocellular injury in preeclampsia. Cell Stress Chaperones 2009; 14: 151-159.

11 Molvarec A, Derzsy Z, Kocsis J, Boze T, Nagy B, Balogh K, Mako V, Cervenak L, Mezes M, Karadi I, Prohaszka Z, Rigo J Jr. Circulating anti-heat-shock-protein antibodies in normal pregnancy and preeclampsia. Cell Stress Chaperones 2009; 14: 491-498.

12 Nagy B, Varkonyi T, Molvarec A, Lazar L, Hupuczi P, Than NG, Rigo J. Leptin gene (TTTC)(n) microsatellite polymorphism in pre-eclampsia and HELLP syndrome. Clin Chem Lab Med 2009; 47: 1033-1037.

13 Maharaj AS, D'Amore PA. Roles for VEGF in the adult. Microvasc Res 2007; 74 100-113.

14 Maynard SE, Min JY, Merchan J, Lim KH, Li J, Mondal S, Libermann TA, Morgan JP, Sellke FW, Stillman IE, Epstein FH, Sukhatme VP, Karumanchi SA. Excess placental soluble fms-like tyrosine kinase 1 (sFlt1) may contribute to endothelial dysfunction, hypertension, and proteinuria in preeclampsia. J Clin Invest 2003; 111: 649-658.

15 Li Z, Zhang Y, Ying Ma J, Kapoun AM, Shao Q, Kerr I, Lam A, O'Young G, Sannajust F, Stathis P, Schreiner G, Karumanchi SA, Protter AA, Pollitt NS. Recombinant vascula endothelial growth factor 121 attenuates hypertension and improves kidney damage in a rat model of preeclampsia. Hypertension 2007; 50: 686-692.

16 Suzuki H, Ohkuchi A, Matsubara S, Takei Y, Murakami M, Shibuya M, Suzuki M, Sato $Y$. Effect of recombinant placental growth factor 2 on hypertension induced by full-length mouse soluble fms-like tyrosine kinase 1 adenoviral vector in pregnant mice. Hypertension 2009; 54: 1129-1135.

17 Nagamatsu T, Fujii T, Kusumi M, Zou L, Yamashita T, Osuga Y, Momoeda M, Kozuma S, Taketani Y. Cytotrophoblasts up-regulate soluble fms-like tyrosine kinase-1 expression under reduced oxygen: an implication for the placental vascular development and the pathophysiology of preeclampsia. Endocrinology 2004; 145: 4838-4845.

18 Nevo O, Soleymanlou N, Wu Y, Xu J, Kingdom J, Many A, Zamudio S, Caniggia I. Increased expression of sFIt-1 in in vivo and in vitro models of human placental hypoxia is mediated by HIF-1. Am J Physiol Regul Integr Comp Physiol 2006; 291 : R1085-R1093.

19 Levine RJ, Maynard SE, Qian C, Lim KH, England LJ, Yu KF, Schisterman EF, Thadhani R, Sachs BP, Epstein FH, Sibai BM, Sukhatme VP, Karumanchi SA. Circulating angiogenic factors and the risk of preeclampsia. N Engl J Med 2004; 350: 672-683.

20 Masuyama $\mathrm{H}$, Suwaki N, Nakatsukasa $\mathrm{H}$, Masumoto A, Tateishi $Y$, Hiramatrsu $Y$. Circulating angiogenic factors in preeclampsia, gestational proteinuria, and preeclampsia superimposed on chronic glomerulonephritis. Am J Obstet Gynecol 2006; 194: $551-556$

21 Ohkuchi A, Hirashima C, Matsubara S, Suzuki H, Takahashi K, Usui R, Suzuki M. Serum sFIt1:PIGF ratio, PIGF, and soluble endoglin levels in gestational proteinuria. Hypertens Pregnancy 2009; 28: 95-108.

22 Molvarec A, Prohaszka Z, Nagy B, Szalay J, Fust G, Karadi I, Rigo J Jr. Association of elevated serum heat-shock protein 70 concentration with transient hypertension of pregnancy, preeclampsia and superimposed preeclampsia: a case-control study. J Hum Hypertens 2006; 20: 780-786.

23 Molvarec A, Rigo J Jr, Nagy B, Walentin S, Szalay J, Fust G, Karadi I, Prohaszka Z. Serum heat shock protein 70 levels are decreased in normal human pregnancy. J Reprod Immunol 2007; 74: 163-169.

24 Joubert K. Standards of the body mass and body length of birth in Hungary on the basis of the 1990-1996 nation-wide liveborn data. Magy Noorv L 2000; 63: 155-163.

25 Ohkuchi A, Hirashima C, Suzuki H, Takahashi K, Yoshida M, Matsubara S, Suzuki M. Evaluation of a new and automated electrochemiluminescence immunoassay for plasma sFIt-1 and PIGF levels in women with preeclampsia. Hypertens Res 2010; 33: 422-427.

26 Verlohren S, Galindo A, Schlembach D, Zeisler H, Herraiz I, Moertl MG, Pape J, Dudenhausen JW, Denk B, Stepan H. An automated method for the determination of the sFIt-1/PIGF ratio in the assessment of preeclampsia. Am J Obstet Gynecol 2010; 202: 161 e1-161 e11.

27 Lazar L, Nagy B, Ban Z, Nagy GR, Papp Z. Presence of cell-free fetal DNA in plasma of women with ectopic pregnancies. Clin Chem 2006; 52: 1599-1601.

28 Placer ZA, Cushman LL, Johnson BC. Estimation of product of lipid peroxidation (malonyl dialdehyde) in biochemical systems. Anal Biochem 1966; 16: 359-364.

29 Molvarec A, Rigo J Jr, Boze T, Derzsy Z, Cervenak L, Mako V, Gombos T, Udvardy ML, Harsfalvi J, Prohaszka Z. Increased plasma von Willebrand factor antigen levels but normal von Willebrand factor cleaving protease (ADAMTS13) activity in preeclampsia. Thromb Haemost 2009; 101: 305-311.

30 Paternoster D, Stella A, Simioni P, Trovo S, Plebani P, Girolami A. Clotting inhibitors and fibronectin as potential markers in preeclampsia. Int J Gynaecol Obstet 1994; 47: 215-221.

31 Kitamoto Y, Takeya M, Tokunaga H, Tomita K. Glomerular endothelial cells are maintained by vascular endothelial growth factor in the adult kidney. Tohoku J Exp Med 2001; 195: 43-54.

32 Sugimoto H, Hamano Y, Charytan D, Cosgrove D, Kieran M, Sudhakar A, Kalluri R. Neutralization of circulating vascular endothelial growth factor (VEGF) by anti-VEGF antibodies and soluble VEGF receptor 1 (sFlt-1) induces proteinuria. J Biol Chem 2003; 278: 12605-12608.

33 Clark DE, Smith SK, He Y, Day KA, Licence DR, Corps AN, Lammoglia R, Charnock-Jones DS. A vascular endothelial growth factor antagonist is produced by the human placenta and released into the maternal circulation. Biol Reprod 1998; 59: 1540-1548.

34 Johansen M, Redman CW, Wilkins T, Sargent IL. Trophoblast deportation in human pregnancy - its relevance for pre-eclampsia. Placenta 1999; 20: 531-539.

35 Hirashima C, Ohkuchi A, Arai F, Takahashi K, Suzuki H, Watanabe T, Kario K, Matsubara S, Suzuki M. Establishing reference values for both total soluble Fms-like tyrosine kinase 1 and free placental growth factor in pregnant women. Hypertens Res 2005; 28: 727-732.

36 Zhong XY, Holzgreve W, Hahn S. The levels of circulatory cell free fetal DNA in maternal plasma are elevated prior to the onset of preeclampsia. Hypertens Pregnancy 2002; 21: 77-83.

37 Lo YM, Leung TN, Tein MS, Sargent IL, Zhang J, Lau TK, Haines CJ, Redman CW. Quantitative abnormalities of fetal DNA in maternal serum in preeclampsia. Clin Chem 1999; 45: 184-188.

38 Lazar L, Rigo J Jr, Nagy B, Balogh K, Mako V, Cervenak L, Mezes M, Prohaszka Z, Molvarec A. Relationship of circulating cell-free DNA levels to cell-free fetal DNA levels, clinical characteristics and laboratory parameters in preeclampsia. BMC Med Genet 2009; 10: 120.

39 Rajakumar A, Michael HM, Rajakumar PA, Shibata E, Hubel CA, Karumanchi SA, Thadhani R, Wolf M, Harger G, Markovic N. Extra-placental expression of vascular endothelial growth factor receptor-1, (FIt-1) and soluble Flt-1 (sFlt-1), by peripheral blood mononuclear cells (PBMCs) in normotensive and preeclamptic pregnant women. Placenta 2005; 26: 563-573.

40 Roberts JM, Gammill HS. Preeclampsia: recent insights. Hypertension 2005; 46: 1243-1249.

41 Shore VH, Wang TH, Wang CL, Torry RJ, Caudle MR, Torry DS. Vascular endothelial growth factor, placenta growth factor and their receptors in isolated human trophoblast. Placenta 1997; 18: 657-665.

42 Lash GE, Taylor CM, Trew AJ, Cooper S, Anthony FW, Wheeler T, Baker PN. Vascular endothelial growth factor and placental growth factor release in cultured trophoblast cells under different oxygen tensions. Growth Factors 2002; 20: 189-196.

43 Torry DS, Mukherjea D, Arroyo J, Torry RJ. Expression and function of placenta growth factor: implications for abnormal placentation. J Soc Gynecol Investig 2003; 10: $178-188$ 
44 Wolf M, Shah A, Lam C, Martinez A, Smirnakis KV, Epstein FH, Taylor RN, Ecker JL, Karumanchi SA, Thadhani R. Circulating levels of the antiangiogenic marker sFLT-1 are increased in first versus second pregnancies. Am J Obstet Gynecol 2005; 193: 16-22.

45 Jeyabalan A, Powers RW, Durica AR, Harger GF, Roberts JM, Ness RB. Cigarette smoke exposure and angiogenic factors in pregnancy and preeclampsia. Am J Hypertens 2008; 21: 943-947.

46 Suwaki N, Masuyama H, Nakatsukasa H, Masumoto A, Sumida $\mathrm{Y}$, Takamoto $\mathrm{N}$, Hiramatrsu Y. Hypoadiponectinemia and circulating angiogenic factors in overweight patients complicated with pre-eclampsia. Am J Obstet Gynecol 2006; 195: 1687-1692.

47 Ahmad S, Ahmed A. Elevated placental soluble vascular endothelial growth factor receptor-1 inhibits angiogenesis in preeclampsia. Circ Res 2004; 95: 884-891.

48 Nakada E, Walley KR, Nakada T, Hu Y, von Dadelszen P, Boyd JH. Toll-like receptor-3 stimulation upregulates sFLT-1 production by trophoblast cells. Placenta 2009; 30 : 774-779.

49 Levine RJ, Lam C, Qian C, Yu KF, Maynard SE, Sachs BP, Sibai BM, Epstein FH, Romero R, Thadhani R, Karumanchi SA. Soluble endoglin and other circulating antiangiogenic factors in preeclampsia. N Engl J Med 2006; 355: 992-1005.

50 Nadar SK, Karalis I, AI Yemeni E, Blann AD, Lip GY. Plasma markers of angiogenesis in pregnancy induced hypertension. Thromb Haemost 2005; 94: 1071-1076.
51 Hirokoshi K, Maeshima Y, Kobayashi K, Matsuura E, Sugiyama H, Yamasaki Y, Masuyama $\mathrm{H}$, Hiramatsu $\mathrm{Y}$, Makino $\mathrm{H}$. Increase of serum angiopoietin-2 during pregnancy is suppressed in women with preeclampsia. Am J Hypertens 2005; 18: 1181-1188.

52 Hirokoshi K, Maeshima Y, Kobayashi K, Matsuura E, Sugiyama H, Yamasaki Y, Masuyama $\mathrm{H}$, Hiramatsu $\mathrm{Y}$, Makino $\mathrm{H}$. Elevated serum sFlt-1/Ang-2 ratio in women with preeclampsia. Nephron Clin Pract 2007; 106: c43-c50.

53 Ohkuchi A, Hirashima C, Matsubara S, Suzuki H, Takahashi K, Arai F, Watanabe T, Kario K, Suzuki M. Alterations in placental growth factor levels before and after the onset of preeclampsia are more pronounced in women with early onset severe preeclampsia. Hypertens Res 2007; 30: 151-159.

54 Masuyama H, Segawa T, Sumida Y, Masumoto A, Inoue S, Akahori Y, Hiramatsu Y. Different profiles of circulating angiogenic factors and adipocytokines between early- and late-onset pre-eclampsia. BJOG 2010; 117: 314-320.

55 Masuyama H, Nakatsukasa H, Takamoto N, Hiramatsu Y. Correlation between soluble endoglin, vascular endothelial growth factor receptor-1, and adipocytokines in preeclampsia. J Clin Endocrinol Metab 2007; 92: 2672-2679.

56 Nakatsukasa H, Masuyama H, Takamoto N, Hiramatsu Y. Circulating leptin and angiogenic factors in preeclampsia patients. Endocr J 2008; 55: 565-573. 